Michel Deguy est né en 1930 à Paris où il fait des études de lettres et de philosophie. Agrégation de philosophie en 1953. Enseignement à Nantes, puis à Paris-VIII, professeur de lettres. Collaboration à diverses revues. Il fonde en 1964 la Revue de Poésie et en 1977 Po\&sie. Choix de publications: Poèmes de la Presqu'île (1961), Poèmes 1960-1970, Tombeau de Du Bellay (1973), Poèmes II (1970-1980), La Poésie n'est pas seule, court traité de poétique (1987), A ce qui $n$ 'en finit pas (1995).

\title{
$\because 2$
}

\section{À Saint-Pacône à la Zuecca}

O n dort bien à Venise. On se rendort. Ce qui est partout ailleurs malaisé. Je parle de la Venise lagunaire, bien sûr, aux 118 îlots, lacunaire, inondée. La Venise à reflets, à gondoles, à pied et à vapeur. C'était un soir de pleine lune orange comme un Euro sur le Lido depuis la Zuecca ("À Saint-Blaise À la Zuecca," chantonne Musset: la discussion entre nous, cent cinquante ans plus tard, porta sur l'étymologie de Giudecca: "Juiverie?" "Justicerie?" Ile des Relégués? Ou, en vénitien, la courge, zuecca? Les Vénètes ne savaient pas.)

Venise se couche tôt donc. Les garçons hâtent le dîner, cendriers remplacés, noria des pichets, acceleratissimi, ce qui ne veut pas dire ici le train le plus lent; change précipité des assiettes; rempilage des tables et des chaises sur les campos. Un moment, un moment! - Mais pourquoi? Parce qu'ils rentrent dormir à Mestre dans le bruit. À minuit moins un masque. On nous rapporte qu'aux angles des deux rues du seul quartier un peu noctambule (Santa Margherita), les riverains ont porté plainte contre les piétonniers buveurs un peu attardés.

La ville colle au-dedans des yeux... Persistance entoptique pendant des jours après le retour. Son nom de Venise dans Paris... Je ferme (ou ne ferme pas) les yeux dans Paris, et ce n'est pas, voici trois jours, Paris que je vois. Mais toujours encore la Salute, la stèle à Byron au quai S. Toma, la place du Colleone avant de longer le mur de l'Ospedale jusqu'à l'arrêt du vapeur 82, face à l'Ile des tombes, qui nous ramenera par le chenal de l'Arsenal, entre les grands lofts abandonnés, les garages à gondoles, le quai vétuste où court un marin en uniforme comme un 
personnage de Bob Wilson en avance, avant de prendre à droite la rive S. Marco. Mais oui, je sais bien, vous connaissez! Évidemment, que vous connaissez; je sais que vous savez. Le but n'est pas de mentionner un vico, un autel, une prédelle que vous n'auriez pas repérés; une pension, un hors-d'oeuvre...

Les 426 ponts-escaliers, arqués, maintiennent les rives ruelles à bon écart comme une cuisse arrime une barque au quai: les 12780 marches jonglent avec leurs pierres. Les vases communiquent. Je glisse, barque lestée d'images, le long. Le long de la douane, le long du Grassi, du Guggenheim. Les palais glissent le long de la barque.

On part dans Venise pour Venise. On s'embarque pour Venise: les visages se frôlent. Immobiles mus, et souriants, ce n'est pas un au-revoir, la cérémonie des adieux s'esquisse à chaque embarcadère. Les humains se croisent, trompeuse tendresse, comme s'ils ne devaient plus se longer à Venise. Et jamais est allègre comme demain.

La France abandonne le palais de son consulat. Nous avons habité une heure cet étage spacieux sur les quai des zattere, en regard de la Giudecca. Les grands titanics à touristes immortels, grec, français, anglais, descendaient le bras vers la sortie du Lido, vers la mer, immeubles salubres glissant à hauteur du deuxième étage. Hauts plafonds, salons évidés, canapés s'enfonçant lentement. Fin de bail. Le drapeau decevait. Ses couleurs passaient. Plus de canot rapide pour le Consul de France. Plus de livres, de lustres, de gâteaux.

Le ridicule ne tue pas Venise. Les eaux du déluge montent lentement. Elle arrivent par citernes - ce sont cars et trains. Nous ne sommes pas noyés. ("Le monde va finir.") Le cheval de Verrocchio est si haut placé qu'on le verra longtemps encore par son ventre. Cette fois-ci je me lassai du Tintoret. Son côté Ange-en-rasemottes, son côté j'ai-lu-Malraux, son côté dernières-nouvelles-AFP... L'Art de Mémoire se renverse: quelles oeuvres fixent les lieux, nous les attachent? "tiennent le coup" dans le musée général? 